\title{
Willingness to Use Mobile Phone Apps for HIV Prevention Among Men Who Have Sex with Men in London: Web-Based Survey
}

William C Goedel ${ }^{1}$, BA; Jason W Mitchell ${ }^{2}$, PhD; Paul Krebs ${ }^{1}$, PhD; Dustin T Duncan ${ }^{1}$, ScD

${ }^{1}$ Department of Population Health, School of Medicine, New York University, New York, NY, United States

${ }^{2}$ Office of Public Health Studies, University of Hawaii at Manoa, Honolulu, HI, United States

Corresponding Author:

William C Goedel, BA

Department of Population Health

School of Medicine

New York University

227 East 30th Street

New York, NY,

United States

Phone: 16465012715

Fax: 16465012706

Email: wcg219@nyu.edu

\section{Abstract}

Background: Many men who have sex with men (MSM) use apps to connect with and meet other MSM. Given that these apps are often used to arrange sexual encounters, it is possible that apps may be suitable venues for messages and initiatives related to HIV prevention such as those to increase HIV testing rates among this population.

Objective: The purpose of this study was to assess willingness to use a new app for reminders of when to be tested for HIV infection among a sample of MSM in London who use apps to arrange sexual encounters.

Methods: Broadcast advertisements targeted users of a popular social-networking app for MSM in London. Advertisements directed users to a Web-based survey of sexual behaviors and sexual health needs. Willingness to use apps for reminders of when to be tested for HIV was assessed. In addition, participants responded to items assessing recent sexual behaviors, substance use, and demographic characteristics. Exploratory analyses were undertaken to examine differences in willingness to use an app by demographic and behavioral characteristics.

Results: Broadcast advertisements yielded a sample of 169 HIV-negative MSM. Overall, two-thirds (108/169, 63.9\%) reported willingness to use an app to remind them when to be tested for HIV. There were no significant differences in willingness to use these apps based on demographic characteristics, but MSM who reported recent binge drinking and recent club drug use more frequently reported willingness to use this app compared to their nonusing counterparts.

Conclusions: MSM in this sample are willing to use a new app for HIV testing reminders. Given the high levels of willingness to use them, these types of apps should be developed, evaluated, and made available for this population.

(JMIR Mhealth Uhealth 2017;5(10):e153) doi: 10.2196/mhealth.8143

\section{KEYWORDS}

mobile phone apps; mHealth; men who have sex with men (MSM); HIV

\section{Introduction}

The human immunodeficiency virus (HIV) epidemic in the United Kingdom impacts gay, bisexual, and other men who have sex with men (MSM) at a disproportionate rate compared to the general population. MSM are estimated to represent 3.3\% of the male population in the United Kingdom but represent between $66.7 \%$ and $69.0 \%$ of all males living with HIV infection as of 2015 and $73.0 \%$ of newly diagnosed HIV infections among males in 2015 [1]. It is estimated that between $7.2 \%$ and $18.9 \%$ of HIV-infected MSM are unaware of their infection status and that $30.0 \%$ of newly diagnosed HIV-infected MSM are diagnosed "late" (ie, with a CD4 count of less than 350 cells per cubic millimeter within 3 months of diagnosis) [1]. Regular HIV testing has a number of important benefits for MSM who test positive and who test negative. For MSM who test negative, 
HIV testing provides the opportunity for risk reduction counseling to encourage behavior change that reduces risk for HIV infection and allows the individual to remain HIV negative [2]. For MSM who test positive, HIV testing improves early awareness of infection status and linkage to care [3]. New interventions to increase HIV testing frequency among MSM in the United Kingdom are needed to further identify new cases of HIV infection and effectively link them to treatment and to reduce engagement in risk behaviors by HIV-uninfected and HIV-infected MSM.

For the past decade, the Internet has been used to deliver and disseminate HIV prevention interventions to diverse populations, including gay, bisexual, and other MSM [4]. Frequently, these interventions have included virtual scenarios and simulations, decision making with virtual characters, and detailed answers or feedback following knowledge tests. For example, Health mPowerment, an intervention based on the Institute of Medicine's integrated model of behavior theory aimed at increasing HIV and sexually transmitted infection (STI) knowledge among young black MSM, incorporates live chats with outreach workers, quizzes, personalized health and journals of sexual activities, and decision support tools for assessing risk behaviors on a single website [5]. Building on these Internet-based interventions and keeping with the pace of technological developments, mobile phone-based HIV prevention interventions are currently in various stages of development and testing. Many of these mobile phone-based interventions incorporate text messaging delivery and have demonstrated some success. For example, Bourne and colleagues [6] found that MSM who enrolled in a text message-based intervention involving reminders for HIV/STI testing tailored based on participant risk behaviors and ability to return for testing were over 4 times more likely to retest for HIV and other STIs compared to those who did not receive the intervention.

Given the pervasiveness of mobile phones and associated apps [7], it may be best to incorporate and adapt aspects of these previously developed Internet- and text message-based interventions for delivery via apps, but it should be noted that their effectiveness is dependent on their continual use, as many individuals download health-related apps and discontinue using them for a variety of reasons [8]. The use of geosocial-networking apps, those that use Global Positioning System (GPS) technology to facilitate various types of connections between MSM, is common among MSM [9-11]. There is no clear consensus in the extant literature regarding the association between meeting sexual partners online or through apps and increased HIV risk behaviors [12]. It has been hypothesized that these digital venues may facilitate multiple partnerships and other HIV risk behaviors for MSM who already engage in these behaviors rather than act as a catalyst for these behaviors themselves [12]. However, while social and sexual network apps are accepted by MSM for HIV prevention and sexual health messaging [13], some companies who produce these geosocial-networking apps are ambiguous in their willingness to support HIV prevention programs [14].

Therefore, the development of new apps for HIV prevention purposes targeted to those potentially high-risk MSM who already use apps to meet sexual partners may be beneficial, but little is known about MSM willingness to engage with new app-related HIV prevention services. As such, the purpose of this study was to examine the willingness to use apps for HIV prevention purposes among a sample of MSM in London recruited from a popular geosocial-networking app used by MSM to meet sexual partners. In exploratory analyses, we examined differences in willingness to use these apps by demographic characteristics and recent sexual and substance use behaviors. This study specifically focused on London because it is an urban epicenter with a high prevalence of HIV among MSM [15] and a high number of MSM who use apps to meet sexual partners [16].

\section{Methods}

\section{Sample Recruitment}

Broadcast advertisements were placed on a popular geosocial-networking app commonly used by MSM to meet sexual partners in January 2016. These broadcasts were targeted specifically to the London metropolitan area. Consistent with recent research among MSM who use apps to meet sexual partners [9], users were shown an advertisement the first time they logged in to the app during four 24-hour periods [17]. The advertisement contained text encouraging users to click through to complete an anonymous Web-based survey on the health of gay and bisexual men in the United Kingdom. Participants were told that completing the survey would enter them in a lottery for a chance to earn $£ 50$ (US \$67). At the end of the recruitment period, 1410 users had clicked through the advertisement and 202 users completed the survey, representing a cooperation rate of $14.33 \%$. All protocols were approved via institutional review board prior to data collection.

\section{Survey Measures}

\section{Willingness to Use Mobile Phone Apps for HIV Prevention}

Respondents were asked, "How willing would you be to use an app to remind yourself when to get tested for HIV?" The wording of this potential intervention was selected given its alignment with the goals of primary prevention of HIV infection [18]. Using a 5-point Likert scale, response options for this item ranged from very willing to very unwilling. For analytical purposes, these categories were collapsed into willing, undecided, and unwilling.

\section{Geosocial-Networking Mobile Phone App Use}

Given that previous research has shown that many individuals who use health-related apps download them and then discontinue using them [8], all respondents were asked, "In the past 12 months, how many times have you deleted and re-downloaded Grindr?" with the aim of understanding consistency of use of geosocial-networking apps to connect with other MSM. Response options for this item included 8 or more times, 6 or 7 times, 4 or 5 times, 2 or 3 times, 1 time, and 0 times.

\section{Recent Sexual Behaviors}

All respondents were asked to report the total number of partners with whom they had insertive and receptive anal intercourse with and without a condom in the preceding 3 months. These 
counts were then dichotomized ( 0 partners vs 1 or more partners).

\section{Recent Substance Use Behaviors}

Respondents were asked to select from a list of substances to indicate any use in the preceding 3 months, included alcohol ( $\geq 5$ drinks in 1 sitting), cocaine, ecstasy, gamma-hydroxybutyric acid or gamma-butyrolactone (GHB/GBL), inhalant nitrites, ketamine, lysergic acid diethylamide (LSD), marijuana, and methamphetamine. Each of these substances was considered individually and a composite variable was created for club drug use (eg, use of ecstasy, GHB/GBL, ketamine, and/or LSD).

\section{Demographic Variables}

Respondents reported their age, sexual orientation, ethnic group membership, employment status, relationship status, and HIV status. Age was measured continuously in years and categorized as aged 18 to 24 years, 25 to 30 years, 31 to 40 years, 41 to 50 years, and 51 years and older. Sexual orientation was categorized as gay, bisexual, straight, and other. Ethnic group membership was categorized as white, black, Asian, and mixed/multiple ethnic groups/other. Employment status was categorized as employed, unemployed, retired, or student. Relationship status was categorized as being in a primary relationship with another man or not. HIV status was assessed based on self-report as negative or positive.

\section{Statistical Analyses}

Broadcast advertisements yielded an overall sample of 202 respondents within 96 hours. A total of 10 individuals who did not report their HIV status and 23 who self-reported as HIV-positive were excluded, restricting the analytical sample to 169 respondents. Descriptive statistics were calculated for all variables. Differences in willingness to use apps for HIV prevention purposes by demographic variables, recent substance use, and categorical measures of recent sexual behaviors were assessed using chi-square tests of independence. Significance was determined as $P<.05$.

\section{Results}

\section{Sample Demographics}

The average age of the sample was 36.7 (SD 11.5) years. A majority $(165 / 169,97.9 \%)$ self-identified as gay or bisexual. Almost three-fourths $(122 / 169,72.4 \%)$ identified their ethnic group as white or white British. A large percentage (144/169, $85.5 \%$ ) were either currently employed or enrolled in school.
Approximately one-fifth $(32 / 169,18.8 \%)$ reported currently being in a relationship with another man.

\section{Recent Sexual Behaviors}

Three-quarters of respondents $(127 / 169,75.2 \%)$ engaged in insertive anal intercourse in the preceding 3 months. Among respondents who had engaged in insertive anal intercourse, $59.9 \%(76 / 127)$ engaged in condomless insertive anal intercourse with 1 or more partners. Almost two-thirds of respondents $(110 / 169,64.9 \%)$ engaged in receptive anal intercourse in the preceding 3 months. Among respondents who had engaged in receptive anal intercourse, 57.3\% (63/110) engaged in condomless receptive anal intercourse with 1 or more partners. About two-fifths of respondents (72/169, 42.6\%) had engaged in a group sex event in the preceding 3 months.

\section{Recent Substance Use Behaviors}

Two-fifths of respondents $(65 / 169,38.6 \%)$ reported having had 5 or more drinks containing alcohol in 1 sitting in the preceding 3 months. With regard to other substances, 36.6\% (62/169) reported using inhalant nitrites, 23\% (39/169) reported using club drugs, $19.8 \%$ (33/169) reported using marijuana, $14.4 \%$ $(24 / 169)$ reported using cocaine or crack cocaine, and $13.9 \%$ (23/169) reported using methamphetamine in the preceding 3 months.

\section{Geosocial-Networking Mobile Phone App Use}

About half of respondents $(82 / 169,48.5 \%)$ had not deleted Grindr in the preceding year. Among those who had deleted and re-downloaded Grindr in the preceding year, 69.2\% (57/82) had deleted and re-downloaded the app 3 or fewer times.

\section{Willingness to Use Mobile Phone Apps for HIV Prevention}

Descriptive statistics are displayed in Table 1. Among the sample, 63.9\% (108/169) were willing to use an app to remind them to get tested for HIV, $24.9 \%$ (42/169) were undecided, and $11.2 \%(19 / 169)$ were unwilling.

Exploratory analyses examining differences in self-reported willingness to use an app for HIV prevention by demographic characteristics (eg, age, ethnic group membership) and recent sexual (eg, engagement in condomless insertive anal intercourse) and substance use (eg, alcohol use, club drug use) behaviors are shown in Table 1. Respondents who reported binge drinking $(P=.03)$ and club drug use $(P=.04)$ more frequently reported more willingness to use an app for HIV testing reminders than their nonusing counterparts. 
Table 1. Willingness to use an app for HIV testing reminders among HIV-negative men who have sex with men recruited from a popular social-networking app in London $(n=169)$.

\begin{tabular}{|c|c|c|c|}
\hline Demographic/behavioral characteristic & Frequency, n (\%) & Rated very willing/willing, $\mathrm{n}(\%)$ & $P$ value \\
\hline Age, years & & & .69 \\
\hline 18 to 24 & $30(16.8)$ & $18(69.3)$ & \\
\hline 25 to 30 & $46(25.7)$ & $24(54.6)$ & \\
\hline 31 to 40 & $55(30.7)$ & $36(70.6)$ & \\
\hline 41 to 50 & $30(16.8)$ & $17(56.6)$ & \\
\hline 51 and older & $18(10.1)$ & $13(72.2)$ & \\
\hline Sexual orientation & & & .80 \\
\hline Gay & $156(87.2)$ & $92(62.4)$ & \\
\hline Bisexual & $19(10.6)$ & $13(76.5)$ & \\
\hline Other & $4(2.2)$ & $2(66.7)$ & \\
\hline Ethnic group membership & & & .99 \\
\hline White/white British & $128(71.5)$ & $80(65.6)$ & \\
\hline Black/black British & $10(5.6)$ & $6(66.6)$ & \\
\hline Asian/Asian British & $14(7.8)$ & $6(54.6)$ & \\
\hline Mixed/multiple ethnic groups/other & $25(14.0)$ & $14(56.0)$ & \\
\hline Employment status & & & .33 \\
\hline Employed & $133(74.3)$ & $80(62.6)$ & \\
\hline Unemployed & $17(9.5)$ & $9(60.0)$ & \\
\hline Student & $23(12.8)$ & $13(75.0)$ & \\
\hline Retired & $5(2.8)$ & $5(100.0)$ & \\
\hline Primary relationship with man & & & .97 \\
\hline Yes & $32(17.9)$ & $18(62.0)$ & \\
\hline No & $147(82.1)$ & $90(64.2)$ & \\
\hline \multicolumn{4}{|l|}{ Recent sexual behaviors } \\
\hline Condomless receptive anal intercourse & $62(34.6)$ & $39(69.6)$ & .09 \\
\hline Condomless insertive anal intercourse & $76(42.5)$ & $47(65.8)$ & .50 \\
\hline \multicolumn{4}{|l|}{ Recent substance use } \\
\hline Alcohol ( $\geq 5$ drinks in a row) & $71(397)$ & $48(71.6)$ & .03 \\
\hline Cocaine & $26(14.5)$ & $15(62.5)$ & .18 \\
\hline Club drugs & $40(22.3)$ & $30(78.9)$ & .04 \\
\hline Inhalant nitrites & $63(35.2)$ & $43(70.5)$ & .69 \\
\hline Marijuana & $38(21.2)$ & $24(66.7)$ & .94 \\
\hline Methamphetamine & $21(11.7)$ & $18(90.0)$ & .12 \\
\hline
\end{tabular}

\section{Discussion}

\section{Principal Findings}

This is the first study to examine the acceptability of the use of mobile phone apps for HIV testing reminders among a sample of MSM in London who use geosocial-networking apps to meet other MSM. Overall, respondents reported a willingness to use an app to remind them to be periodically tested for HIV (108/169, or 63.9\%, rated themselves as willing or very willing). Our findings are similar to those observed among a sample of young MSM in Southern California, where about $70.0 \%$ (137/195) were willing to participate in an HIV prevention program delivered via an app [19]. In addition, we found no significant differences in willingness to use these apps based on demographic characteristics or sexual behaviors. The lack of significant variations in willingness to use these apps across most subgroups in this sample of MSM suggests that these intervention tools can be implemented in diverse populations of MSM living in London. However, the presence of significant differences among MSM who reported binge drinking and club drug use may suggest a need for targeted prevention-related 
apps for these populations so that they can manage their HIV-related risks and substance use-related risks concurrently.

Given the high prevalence of inconsistent use of geosocial-networking apps to meet sexual partners in the preceding 12 months (where $87 / 169$, or $51.5 \%$, reported deleting and re-downloading the app at least once), the implementation of these interventions should include strategies to encourage consistency of use. Recent formative qualitative research has aimed at assessing factors associated with consistency of use. Among samples of HIV-negative MSM in Miami and Minneapolis, reliability, ease of use, and frequency of updates were cited as factors associated with whether an individual would keep and continue to use an app over time while poor performance and functionality and lack of use were primary reasons why MSM would delete an app from their phone [20]. The item used in this study examines consistency of use of social-networking apps, and this may not reflect potential consistency of use of health-related apps or HIV prevention-related apps. However, it is possible that HIV prevention-related features of app-based interventions may be more consistently used if integrated into an existing social-networking platform.

Future research is needed to identify and test potential apps to be used for HIV testing reminders among MSM who use geosocial-networking apps to meet sexual partners, particularly in contexts other than the United States, given that this is where most of the previous research has been conducted [21,22]. However, it is possible that the features of apps desired by MSM in the United States may be similar to those desired by MSM elsewhere. Previous research with HIV-negative MSM has suggested that apps for HIV prevention should encourage regular HIV testing by providing feedback on test reminders, tailored testing interval recommendations, and HIV test site-locating features [20]. In addition, these apps should be designed to be discrete in nature, protect privacy, and not necessarily appear overtly to be related to HIV prevention. Should another individual, for example, see an app explicitly for HIV prevention, it could expose an individual to HIV-related stigma (if others assume they are HIV-positive) and discourage them from using these types of apps.

\section{Limitations}

These findings are not without limitations. These findings are derived from data collected as part of a convenience sample of MSM from a single popular geosocial-networking app in a single metropolitan center in Western Europe. As such, these findings are likely not generalizable to broader populations of MSM on other apps or outside of these apps. These findings are also likely biased by some degree of self-selection, where those who are willing to engage with communication regarding HIV prevention via apps may have been more likely to participate. In addition, our measures of risk behaviors (eg, sexual and substance use behaviors) are crude, and there may be some misclassification with regard to behavioral risk. Future research should use more nuanced measures of these behaviors (eg, number of events of condomless receptive anal intercourse with a serodiscordant or unknown HIV status partner in a recall period, number of times using methamphetamine in a recall period) to further our understanding of the behavioral risk profiles of MSM who are willing to use apps for HIV prevention.

\section{Conclusion}

The majority of respondents in this sample of MSM who use apps to meet other MSM reported willingness to use an app to remind them to be tested for HIV infections. Apps to be used for HIV prevention interventions, such as those aimed at increasing HIV testing rates among MSM (particularly those who are already using apps to meet other MSM), should be developed, evaluated, and implemented.

\section{Conflicts of Interest}

None declared.

\section{References}

1. Public Health England. HIV in the United Kingdom. URL: https://www.gov.uk/government/uploads/system/uploads/ attachment data/file/602942/HIV in the UK report.pdf [accessed 2017-09-28] [WebCite Cache ID 6tp2E2y2O]

2. Wolitski RJ, MacGowan RJ, Higgins DL, Jorgensen CM. The effects of HIV counseling and testing on risk-related practices and help-seeking behavior. AIDS Educ Prev 1997 Jun;9(3 Suppl):52-67. [Medline: 9241398]

3. Ulett KB, Willig JH, Lin H, Routman JS, Abroms S, Allison J, et al. The therapeutic implications of timely linkage and early retention in HIV care. AIDS Patient Care STDS 2009 Jan;23(1):41-49 [FREE Full text] [doi: 10.1089/apc.2008.0132] [Medline: 19055408]

4. Ybarra ML, Bull SS. Current trends in Internet- and cell phone-based HIV prevention and intervention programs. Curr HIV/AIDS Rep 2007 Dec;4(4):201-207. [Medline: 18366952]

5. Hightow-Weidman LB, Fowler B, Kibe J, McCoy R, Pike E, Calabria M, et al. HealthMpowerment.org: development of a theory-based HIV/STI website for young black MSM. AIDS Educ Prev 2011 Feb;23(1):1-12 [FREE Full text] [doi: 10.1521/aeap.2011.23.1.1] [Medline: 21341956]

6. Bourne C, Knight V, Guy R, Wand H, Lu H, McNulty A. Short message service reminder intervention doubles sexually transmitted infection/HIV re-testing rates among men who have sex with men. Sex Transm Infect 2011 Apr;87(3):229-231. [doi: 10.1136/sti.2010.048397] [Medline: 21296796] 
7. Smith A. US smartphone use in 2015. Washington: Pew Internet and American Life Project URL: http://assets. pewresearch.org/wp-content/uploads/sites/14/2015/03/PI Smartphones 0401151.pdf [accessed 2017-09-28] [WebCite Cache ID 6tp2OWADW]

8. Krebs P, Duncan DT. Health app use among US mobile phone owners: a national survey. JMIR Mhealth Uhealth 2015;3(4):e101 [FREE Full text] [doi: 10.2196/mhealth.4924] [Medline: 26537656]

9. Goedel WC, Duncan DT. Geosocial-networking app usage patterns of gay, bisexual, and other men who have sex with men: survey among users of Grindr, a mobile dating app. JMIR Public Health Surveill 2015;1(1):e4 [FREE Full text] [doi: 10.2196/publichealth.4353] [Medline: 27227127]

10. Lehmiller JJ, Ioerger M. Social networking smartphone applications and sexual health outcomes among men who have sex with men. PLoS One 2014;9(1):e86603 [FREE Full text] [doi: 10.1371/journal.pone.0086603] [Medline: 24466166]

11. Landovitz RJ, Tseng C, Weissman M, Haymer M, Mendenhall B, Rogers K, et al. Epidemiology, sexual risk behavior, and HIV prevention practices of men who have sex with men using GRINDR in Los Angeles, California. J Urban Health 2013 Aug;90(4):729-739 [FREE Full text] [doi: 10.1007/s11524-012-9766-7] [Medline: 22983721]

12. Zou H, Fan S. Characteristics of men who have sex with men who use smartphone geosocial networking applications and implications for HIV interventions: a systematic review and meta-analysis. Arch Sex Behav 2017 May;46(4):885-894. [doi: 10.1007/s10508-016-0709-3] [Medline: 27043837]

13. Sun CJ, Stowers J, Miller C, Bachmann LH, Rhodes SD. Acceptability and feasibility of using established geosocial and sexual networking mobile applications to promote HIV and STD testing among men who have sex with men. AIDS Behav 2015 Mar;19(3):543-552. [doi: 10.1007/s10461-014-0942-5] [Medline: 25381563]

14. Chan PA, Towey C, Poceta J, Rose J, Bertrand T, Kantor R, et al. Online hookup sites for meeting sexual partners among men who have sex with men in Rhode Island, 2013: a call for public health action. Public Health Rep 2016

Mar;131(2):264-271 [FREE Full text] [doi: 10.1177/003335491613100210] [Medline: 26957661]

15. Desai S, Croxford S, Brown AE, Mitchell H, Hughes G, Delpech V. An overview of the HIV epidemic among men who have sex with men in the United Kingdom, 1999-2013. Euro Surveill 2015 Apr 09;20(14) [FREE Full text] [Medline: 25884147]

16. Grindr. URL: https://www.grindr.com/ [accessed 2017-09-28] [WebCite Cache ID 6tp30s3y9]

17. Duncan DT, Goedel WC, Mayer KH, Safren SA, Palamar JJ, Hagen D, et al. Poor sleep health and its association with mental health, substance use, and condomless anal intercourse among gay, bisexual, and other men who have sex with men. Sleep Health 2016 Dec;2(4):316-321. [doi: 10.1016/j.sleh.2016.07.003]

18. Kelly JA, Kalichman SC. Behavioral research in HIV/AIDS primary and secondary prevention: recent advances and future directions. J Consult Clin Psychol 2002 Jun;70(3):626-639 [FREE Full text] [Medline: 12090373]

19. Holloway IW, Rice E, Gibbs J, Winetrobe H, Dunlap S, Rhoades H. Acceptability of smartphone application-based HIV prevention among young men who have sex with men. AIDS Behav 2014 Feb;18(2):285-296 [FREE Full text] [doi: 10.1007/s10461-013-0671-1] [Medline: 24292281]

20. Mitchell JW, Torres MB, Joe J, Danh T, Gass B, Horvath KJ. Formative work to develop a tailored HIV testing smartphone app for diverse, at-risk, HIV-negative men who have sex with men: a focus group study. JMIR Mhealth Uhealth 2016 Nov 16;4(4):e128 [FREE Full text] [doi: 10.2196/mhealth.6178] [Medline: 27852558]

21. Goldenberg T, McDougal SJ, Sullivan PS, Stekler JD, Stephenson R. Preferences for a mobile HIV prevention app for men who have sex with men. JMIR Mhealth Uhealth 2014;2(4):e47 [FREE Full text] [doi: 10.2196/mhealth.3745] [Medline: 25355249]

22. Muessig KE, Nekkanti M, Bauermeister J, Bull S, Hightow-Weidman LB. A systematic review of recent smartphone, Internet and Web 2.0 interventions to address the HIV continuum of care. Curr HIV/AIDS Rep 2015 Mar;12(1):173-190 [FREE Full text] [doi: 10.1007/s11904-014-0239-3] [Medline: 25626718]
Abbreviations
GBL: gamma-butyrolactone
GHB: gamma-hydroxybutyric acid
GPS: Global Positioning System
HIV: human immunodeficiency virus
LSD: lysergic acid diethylamide
MSM: men who have sex with men
STI: sexually transmitted infection 
Edited by C Dias; submitted 02.06.17; peer-reviewed by J Uhrig, C Shen; comments to author 21.06.17; revised version received 18.07.17; accepted 13.08.17; published 11.10.17

Please cite as:

Goedel WC, Mitchell JW, Krebs P, Duncan DT

Willingness to Use Mobile Phone Apps for HIV Prevention Among Men Who Have Sex with Men in London: Web-Based Survey

JMIR Mhealth Uhealth 2017;5(10):e153

URL: http://mhealth.jmir.org/2017/10/e153/

doi: $10.2196 /$ mhealth. 8143

PMID: 29021132

(CWilliam C Goedel, Jason W Mitchell, Paul Krebs, Dustin T Duncan. Originally published in JMIR Mhealth and Uhealth (http://mhealth.jmir.org), 11.10.2017. This is an open-access article distributed under the terms of the Creative Commons Attribution License (https://creativecommons.org/licenses/by/4.0/), which permits unrestricted use, distribution, and reproduction in any medium, provided the original work, first published in JMIR mhealth and uhealth, is properly cited. The complete bibliographic information, a link to the original publication on http://mhealth.jmir.org/, as well as this copyright and license information must be included. 